\title{
1 Effects of simulated light regimes on gene expression in Antarctic krill
}

\section{2 (Euphausia superba Dana)}

3

4 Paul Seear ${ }^{\mathrm{a}, *}$, Geraint A. Tarling ${ }^{\mathrm{a}}$, Mathias Teschke ${ }^{\mathrm{b}}$, Bettina Meyer ${ }^{\mathrm{b}}$, Michael A. S. Thorne ${ }^{\mathrm{a}}$,

$5 \quad$ Melody S. Clark ${ }^{\mathrm{a}}$, Edward Gaten ${ }^{\mathrm{c}}$, Ezio Rosato ${ }^{\mathrm{d}}$

6

7

${ }^{a}$ British Antarctic Survey, High Cross, Madingley Rd, Cambridge, CB3 0ET, UK

${ }^{\mathrm{b}}$ Alfred Wegener Institute for Polar and Marine Research, Scientific Division Biological Oceanography, Handelshafen 12, 27570 Bremerhaven, Germany

${ }^{\mathrm{c}}$ Department of Biology, University of Leicester, University Road, LE1 7RH, UK

${ }^{\mathrm{d}}$ Department of Genetics, University of Leicester, University Road, LE1 7RH, UK

*Corresponding author. Tel. +44 1223 221346. E-mail address: paea@bas.ac.uk

ABSTRACT

A change in photoperiod has been implicated in triggering a transition from an active to a quiescent state in Antarctic krill. We examined this process at the molecular level, to identify processes that are affected when passing a photoperiodic threshold. Antarctic krill captured in the austral autumn were divided into two groups and immediately incubated either under a photoperiod of 12 hours light: 12 hours darkness (LD), simulating the natural light cycle, or in continuous darkness (DD), simulating winter. All other conditions were kept identical between incubations. After 7 days of adaptation, krill were sampled every 4 hours over a 24 hour period and frozen. Total RNA was extracted from the heads and pooled to construct a suppression subtractive hybridisation library. Differentially expressed sequences were 
27 identified and annotated into functional categories through database sequence matching. We

28 found a difference in gene expression between LD and DD krill, with LD krill expressing

29 more genes involved in functions such as metabolism, motor activity, protein binding and

30 various other cellular activities. Eleven of these genes were examined further with

31 quantitative polymerase chain reaction analyses, which revealed that expression levels were

32 significantly higher in LD krill. The genes affected by simulated photoperiodic change are

33 consistent with known features of quiescence, such as a slowing of moult rate, a lowering of

34 activity levels and a reduction in metabolic rate. The expression of proteases involved in

35 apolysis, where the old cuticle separates from the epidermis, showed particular sensitivity to

36 photoperiod and point to the mechanism by which moult rate is adjusted seasonally. Our

37 results show that key processes are already responding at the molecular level after just 7 days

38 of exposure to a changed photoperiodic cycle. We propose that krill switch rapidly between

39 active and quiescent states and that the photoperiodic cycle plays a key role in this process.

40

41 Key words: euphausiid; moulting; overwintering; photoperiod; quiescence; Southern Ocean. 


\section{Introduction}

Due to their high latitude, Antarctic krill (Euphausia superba) must endure extreme seasonality, with phytoplankton blooms filling only a few short summer months. The rest of the year is characterised by food-shortage, an encroaching ice-pack and long periods of darkness. Life-cycle strategies in these environments must include a means of saving energy during the non-productive periods (Dahms 1995). As a result, a number of key marine plankton taxa in the Southern Ocean exhibit some sort of reduced activity during the winter months. The calanoid copepods Calanoides acutus and Rhincalanus gigas, for instance, enter a classic diapause (Hirche 1996) where they arrest development, lower metabolism, reduce levels of activity and descend to great depths (Schnack-Shiel and Hagen 1994). The strategy of Antarctic krill (E. superba) is less clear-cut since, despite the potentially large energy shortfall, they remain within the upper water column during the winter (Godlewska 1996).

Some have proposed that, in the absence of preferred foods such as diatoms, Antarctic krill switch to alternative food sources, such as ice biota (Marschall, 1988), zooplankton (Huntley et al., 1994) and seafloor detritus (Kawaguchi et al., 1986). However, feeding experiments on E. superba during autumn in the Lazarev Sea (Atkinson et al., 2002) found that oxygen uptake and clearance rates were three times lower than in summer (Atkinson and Snyder, 1997). Quetin et al. (2003) found that growth rates of larval and juvenile krill were minimal in early winter. Moult rate in adult Antarctic krill has been observed to slow down or even stop during winter-time (Clarke 1976). It therefore appears that krill can potentially employ a strategy of "quiescence" (Hirche, 1996), through retarding feeding activity, metabolism and growth to outlast the winter period. 
In line with the definitions used with respect to dormancy in insects (Danks 1987), we use the term quiescence here to mean a type of dormancy in which life-processes are retarded in direct response to a limiting factor (e.g. low temperature, limiting food) without prior acclimation. This distinguishes it from diapause, which is an arrest in development that may be triggered by environmental factors and is compulsory and ultimately genetically determined. Both the onset of quiescence and diapause may be triggered by a variety of cues, including chemical (Slusarczyk and Rygielska, 2004, Pijanowska and Stolpe, 1996), thermal (Jewson et al., 2008) and photoperiodic (Chinnery and Williams, 2003). Others have proposed the involvement of internal clocks, such as Tande and Hopkins (1981), who linked the timing of the re-appearance of the calanoid copepod, Calanus finmarchicus in surface waters to the gradual development of the gonads over winter. Nevertheless, internal clocks are frequently synchronised by external cues, or zeitgebers (Buchholz 1991). If krill do alternate between distinct physiological states in response to productive and non-productive seasons, it is likely that there is a cue which triggers this change of state.

Teschke et al. $(2007,2008)$ focused on photoperiod as a potential cue by which key life-cycle processes in Antarctic krill are co-ordinated, based on evidence by Hirano et al. (2003) of its involvement in maturation and spawning. Winter-time krill were exposed to three different photoperiod cycles, continuous darkness (DD), 12 hours light: 12 hours darkness (LD) and continuous light (LL) for three months. Constant temperature was maintained and food was kept abundant across all incubations. Results showed a marked difference in the state of those krill kept in DD compared with those exposed to LL or LD, with individuals maintained in LL or LD showing increased rates of metabolism (oxygen uptake rates, metabolic enzyme activity) and feeding activity (digestive gland size, clearance rate, digestive enzyme activity), and the development of external secondary sexual organs. These experiments suggest, firstly, 
93 that krill switch between active and quiescent physiological states and, secondly, that

94 photoperiodic cycles are a major cue in causing this switch.

95

96 Molecular approaches are a useful way of examining the processes involved in switching

97 between physiological states since they foretell the physiological changes that will

98 subsequently occur. In one of the only studies on gene expression during diapause in marine

99 zooplankton, Tarrant et al. (2008) examined the differences in gene expression between

100 active and diapausing C. finmarchicus. They found that genes associated with lipid synthesis,

101 transport and storage were more highly expressed in active copepods, while diapausing

102 copepods showed greater expression of the gene ferritin, encoding for an iron sequestering

103 protein that also acts as a molecular chaperone; properties that may help protect cells from

104 oxidative and thermal stress (Chen et al. 2007).

105

106 Underlying the approach of Tarrant et al. (2008) were two key techniques: suppression

107 subtractive hybridisation ( $\mathrm{SSH}$ ) and quantitative PCR (qPCR). SSH is a means of comparing

108 the genes that are expressed by two populations exposed to different conditions and

109 maximising the identification of genes uniquely expressed in one or other population. qPCR

110 is then employed to determine to what degree a gene is differentially expressed between

111 populations. The use of these techniques is now widespread and, in addition to the study of

112 Tarrant et al. (2008), have been used to examine dauer larvae in the nematode Caenorhabditis

113 elegans (Cherkasova et al. 2000) and diapause in the mosquito, Culex pipens (Robich et al.

114 2007).

115

116 In this study, we investigated how gene transcription changes during the transition from

117 summer-time activity to winter-time quiescence in Antarctic krill. Krill caught in autumn 
118 were exposed to either, 12 hours light: 12 hours darkness (LD), simulating autumn, or

119 continuous darkness (DD), simulating winter, for seven days. SSH and qPCR were then used

120 to identify genes that were differentially expressed between the two populations and to

121 characterise the level of up or down regulation. The probable function of these genes within

122 physiological processes was investigated through database searches and comparison to

123 homologues in other organisms. This study represents one the first applications of genomic

124 tools to understand the regulation of physiological processes in Antarctic krill.

125 
Materials and methods

127

128 Experimental design

129 Live Euphausia superba were collected using a Rectangular Midwater Trawl net (RMT1+8)

130 in the upper $200 \mathrm{~m}$ of the water column on 14 March $2004\left(65^{\circ} 15^{\prime} \mathrm{S}, 4^{\circ} 45^{\prime} \mathrm{W}\right)$ by RV

131 Polarstern (ANTXXI-4). Immediately after capture, adult krill of mixed sex were transferred

132 into $65 \mathrm{~L}$ tanks (30 krill in each) filled with natural sea water, which were located in separate

133 constant temperature rooms at $0{ }^{\circ} \mathrm{C}$. Photoperiod and light intensity were controlled in each

134 room by a PC-controlled timer system. The tanks were exposed to one of the following light

135 regimes to simulate Southern Ocean autumn and winter conditions respectively: experimental

136 tank (1) autumn: 12 hours light and 12 hours darkness (LD) with a maximum of 50 lux light

137 intensity at the surface of the tank during midday; and experimental tank (2) winter:

138 continuous darkness (DD) (Fig. 1). 50\% of the incubation water was exchanged daily. Twice

139 a day, moults and a small number of dead animals were removed from the tanks. After 7 days

140 of adaptation to these conditions, three krill were sub-sampled every 4 hours from each

141 experimental tank over a 24 hour time period. In total, 21 krill were extracted from each tank.

142 Sampled krill were immediately frozen in liquid nitrogen and stored at $-80{ }^{\circ} \mathrm{C}$ for further

143 analyses. Sampling during dark periods was performed in dim red light.

\section{SSH library construction}

146 Total RNA was extracted from the heads of frozen $\left(-80^{\circ} \mathrm{C}\right)$ E. superba using the RNeasy

147 Midi kit (Qiagen) following manufacturer's instructions. RNA was resuspended in DEPC-

148 treated water and the concentration determined using a NanoDrop spectrophotometer

149 (LabTech International). Total RNA was pooled from 21 LD krill and 21 DD krill before

150 isolating mRNA from each pool using a MicroPoly(A) Purist ${ }^{\mathrm{TM}}$ kit (Applied Biosystems). 
151 Each pool of krill consisted of three krill sampled every four hours, over a 24 hour time

152 period. One microgram of LD and DD mRNA was used in the construction of a SSH library

153 using the PCR-Select ${ }^{\mathrm{TM}}$ cDNA Subtraction kit (Clontech) following manufacturer's

154 instructions, in which LD cDNA was the tester and DD cDNA was the driver. In addition to

155 the SSH library, a library was also made of Rsa I digested LD cDNA that had not undergone

156 subtraction with DD cDNA to act as a control. Subtracted and non-subtracted cDNAs were

157 cloned into pGEM $^{\circledR}$-T Easy (Promega) before being transformed to Escherichia coli XL2-

158 Blue MRF' cells (Agilent Technologies). Recombinant clones identified by blue/white

159 selection were grown in $100 \mu \mathrm{TB}$ medium overnight in 96 well plates and $40 \mu 150 \%$

160 glycerol added before storing at $-80{ }^{\circ} \mathrm{C}$.

161

162

cDNA sequencing

163 Prior to sequencing, the inserts of each clone were amplified and purified according to the

164 protocol of Purać et al. (2008), with the substitution of Advantage 2 Polymerase mix and

165 buffer (Clontech) for BIOTAQ ${ }^{\mathrm{TM}}$ DNA polymerase, buffer and $\mathrm{MgCl}_{2}$ (Bioline). Purified

166 PCR products were then sequenced with M13F (5'-GTAAAACGACGGCCAGTGAAT-3')

167 and M13R (5'-AACAGCTATGACCATGATTACG-3') long sequencing primers using Big

168 Dye ${ }^{\circledR}$ Terminator cycle sequencing kits (version 3.1, Applied Biosystems) and an automated

169 DNA sequencer (MegaBACE ${ }^{\mathrm{TM}}$ 1000, GE Healthcare).

170

\section{Sequence analysis}

172 Trace2dbest, (Parkinson et al., 2004) incorporating phred (Ewing and Green, 1998; Ewing et

173 al., 1998) and crossmatch (Green P: unpublished) was used for basecalling and trimming of

174 vectors. Only high quality sequences more than $150 \mathrm{bp}$ in length were used for database

175 searching. In order to examine sequence similarity to known genes, Blastx (Altschul et al., 
176 1997) was used to search Swissprot, Trembl and non-redundant (nr) sequence databases for

177 significant matches. A significant database search was defined as having an expectation value

178 (E-value) below $1 \mathrm{e}^{-5}$. All sequences with an E-value below $1 \mathrm{e}^{-10}$ were further annotated using

179 GO terms and GO slims (The Gene Consortium, 2000). GO enrichment was determined by a

180 one-tailed proportion test at a $\mathrm{p}$ value of less than 0.05 that compared the proportion of clones

181 representing a GO slim term in the subtracted library to the proportion of clones representing

182 the same GO slim term in the unsubtracted library. High quality sequences were submitted to

183 dbEST (Boguski et al., 1993) and given the following accession numbers: dbEST: $\underline{\mathbf{6 0 1 2 5 3 6 7 -}}$

184 60126646, Genbank: FL688135- FL689414.

185

186 Quantitative PCR

187 qPCR sample sets: Two sets of qPCR analysis were performed to compare gene expression

188 between LD and DD krill.

189 1. Pooled krill analysis: The expression of 11 genes selected from the SSH library based on

190 their known, or proposed involvement in moulting, metabolism and motor activity (Table 1)

191 was compared between the same pools of LD and DD krill (each consisting of 21 krill

192 sampled over a 24 hour period) used in the SSH library construction.

193 2. Individual krill analysis: qPCR analysis of a subset of the above 11 genes was performed

194 on individual krill from the LD and DD regimes. Each krill was measured for uropod length,

195 sex and maturity where possible (following Makarov and Denys 1980), and moult stage

196 (following Buchholz 1982). Given that some of the largest differences in gene expression

197 from the pooled-krill analysis were in genes proposed to be involved in moulting (see

198 Results), krill were sorted according to moult stage and compared between LD and DD light

199 regimes. Specifically, we focussed on the stages around apolysis (the point at which the

200 cuticle separates from the epidermis). Stage C (or intermoult) occurs immediately before 
apolysis and D0 (or $1^{\text {st }}$ stage premoult), at the point of apolysis and just after (Fig. 2). We made a number of comparisons to examine how gene expression alters between these two moult stages and how this is affected by the photoperiodic cycle (Table 2).

Primers were designed around the Expressed Sequence Tag (EST) of interest, using Primer 3 (Rozen and Skaletsky, 2000) to generate PCR products of between 100 and $200 \mathrm{bp}$ (Table 3).

To normalise the data, primers were also designed against ESTs with significant homology to the following three potential reference genes; beta actin, glyceraldehyde 3-phosphate dehydrogenase (GAPDH) and phosphoenolpyruvate carboxykinase (PEP-CK). Beta actin was found to be the most stable in the pooled krill analysis, while PEP-CK changed the least in the individual krill analysis.

qPCR methodology: One microgram of total RNA was used to make first strand cDNA using

214 a Quantitect Reverse Transcription kit (Qiagen) that incorporates genomic DNA removal

215 prior to reverse transcription. The cDNA $(20 \mu \mathrm{l})$ was diluted to $80 \mu 1$ and $1 \mu 1$ was used as

216 template for qPCR. The qPCR mixture consisted of $10 \mu 12 \times$ SensiMixPlus SYBR mastermix (Quantace), $600 \mathrm{nM}$ of forward and reverse primers, $1 \mu 1 \mathrm{cDNA}$ and sterile MilliQ water in a total volume of $20 \mu 1$. The qPCRs were performed in duplicate on a Mx3000P QPCR system (Agilent Technologies) with the following cycling conditions: $95^{\circ} \mathrm{C}$ for 10 min, followed by 40 cycles of $95^{\circ} \mathrm{C}$ for $30 \mathrm{sec}, 60^{\circ} \mathrm{C}$ for 1 min and $72{ }^{\circ} \mathrm{C}$ for $30 \mathrm{sec}$. A

221 dissociation curve step was then performed to ensure that only a single product had been amplified in each reaction. Standard curves were performed for each primer pair with a dilution series of cDNA. By plotting threshold crossing cycle $\left(C_{t}\right)$ values against the $\log _{10}$ of

224 the different dilutions, PCR efficiency was calculated as $\mathrm{E}=10^{(-1 / \text { slope })}-1$, using MxPro ${ }^{\mathrm{TM}}$

225 (Agilent Technologies) software. Relative mean expression ratios were statistically compared 
226 between light regimes (LD and DD) and moult stages (C and D0) following normalisation

227 against the reference gene using the relative expression software tool REST (Pfaffl et al.

228 2002). For statistical analysis of relative mean expression ratios, REST employs

229 randomisation tests with a pair-wise reallocation that make no assumptions about the

230 distribution of observations in populations. The software was used to perform 2000 random

231 allocations to determine if the results were due to chance or to the effects of the treatment

232 (light regime or moult stage), with differences considered to be significant at $\mathrm{P}<0.05$.

233

234

235 
Results

237

238

\section{SSH library analysis}

239

A krill LD SSH library was constructed along with an unsubtracted LD library in which no subtraction with DD krill was performed. This allowed a comparison to be made between subtracted and unsubtracted libraries that would indicate which genes were enriched by the subtraction with the DD krill. From each library, 960 clones were sequenced that resulted in 595 and 685 high quality sequences longer than $150 \mathrm{bp}$ from the subtracted and unsubtracted libraries respectively (Table 4). A comparison with the ESTs published in the first sequencing study of Euphausia superba (De Pittà et al., 2008) showed that 581 of these sequences were novel. Following sequence matching to NCBI databases using Blastx, of the putative mRNAs, $225(48 \%)$ and $232(40 \%)$ could be identified from the subtracted and unsubtracted libraries respectively $\left(E<1 \mathrm{e}^{-5}\right)$. Identified genes with an $\mathrm{E}$-value of less than $1 \mathrm{e}^{-10}$ were then annotated using GO slims (a database of simplified gene ontology descriptions) from the Gene Ontology Consortium and placed into different functional categories (Table 5). This table shows that metabolism, protein binding and various other cellular activities are enriched in the subtracted library that may correspond to higher expression of genes in these categories in LD krill.

\section{Quantitative PCR analysis}

256 To measure the level of differential gene expression between LD and DD incubated krill,

257 qPCR was first performed on 11 genes selected from the SSH library based on their known,

258 or proposed, involvement in moulting, metabolism and motor activity (Table 1). The list includes five enzymes and three enzyme precursors. Of the enzymes, aldo-keto reductase and fructose-bisphosphate aldolase are involved in carbohydrate metabolism (Gabbay and Tze, 
1972; Salvatore et al., 1986; Bagnasco et al., 1987), while $\beta$-N-acetylglucosaminidase has been shown to be involved in the degradation of the old cuticle during moulting (Samuels and Reynolds, 1993). CUB-serine protease was included as serine proteases have been found in

264 the moulting fluid of insects (Samuels et al., 1993) and are thought to be involved in the 265 digestion of the old cuticle during the apolysis stage prior to moulting. Trypsin is known to 266 be involved in food protein digestion (Diaz-Mendoza et al., 2005) but it also has protease properties (Muhlia-Almazán et al., 2008) and has been shown to activate other proteases (Tsu and Craik, 1996). As for the enzyme precursors, the activated pancreatic carboxypeptidase A1 precursor is involved in moulting (Ote et al., 2005), while the activated form of the serine collagenase 1 precursor has protease properties (Tsu and Craik, 1996) required for degradation of the old cuticle. Trypsinogen is a precursor of trypsin (Neurath 1964). The other genes in the list encode for cuticle protein CB6, required for formation of new cuticle (Kuballa et al., 2007); myosin light chain protein, involved in motor activity (Poetter et al., 1996) and a low density lipoprotein receptor-related protein involved in both cuticle degradation (Yochem et al., 1999) and protease activation (Krieger and Herz, 1994; Strickland et al., 1995).

277

Pooled krill analysis: All genes selected for qPCR were found to be up regulated in LD krill, although there were differences in the level of up regulation (Fig. 3). Some of the largest differences in gene expression were in genes proposed to be involved at various stages of the moulting process. In particular, large differences between LD and DD krill were observed with the proteases, serine collagenase, trypsin and CUB-serine protease. These results therefore focussed our further efforts onto the interaction between moult stage (particularly the time around apolysis) and photoperiod cycle within individual krill. 
Individual krill analysis: Three qPCR comparisons were made to reveal the effect of stage of moult and photoperiodic cycles on gene expression around the period of apolysis: A, the effect of apolysis on gene expression (LD/DD intermoult or stage C versus LD/DD premoult stage D0); B, the effect of photoperiod immediately before apolysis (LD stage C versus DD stage C); C, the effect of photoperiod immediately after apolysis (LD stage D0 versus DD stage D0). Comparisons were made for three differentially expressed genes, as identified by the pooled-krill analysis, with suspected involvement in the process of apolysis: serine collagenase, trypsin and CUB-serine protease. A fourth gene, cuticle CB6 was also included, given its function in new cuticle formation:

A, there was no significant change in the expression of serine collagenase, trypsin and CUBserine protease before and after apolysis. However, there was a significant up regulation of cuticle CB6 after apolysis (Fig. 4a).

$\mathrm{B}$, serine collagenase, trypsin and CUB-serine protease expression were down regulated significantly $(\mathrm{p}<0.05)$ in DD stage $C$ krill compared with LD stage $C$ krill. Trypsin showed a 200 fold down-regulation in DD krill and serine collagenase, a 140 fold down regulation.

301 There was little difference in the expression of cuticle CB6 (Fig. 4b). $\mathrm{C}$, none of the genes showed a significant change in expression between photoperiod regimes immediately after apolysis i.e. stage D0 (Fig. 4c).

The results reveal a complex picture of up- and down-regulation of genes depending on both

306 photoperiod and moult-stage relative to the point of apolysis. Photoperiod affected the expression of protease genes (serine collagenase, trypsin and CUB-serine protease) only prior to apolysis (stage C) and not after apolysis has occurred (stage D0). Furthermore, postapolysis, the formation of a new cuticle (as indicated by the expression of cuticle CB6)

310 continues irrespective of the photoperiodic cycle. Overall, the DD treatment appeared to 
311 slow-down or even halt processes leading up to apolysis but had little effect on individuals

312 that were post-apolysis and already making preparations for the next moult.

313

314 


\section{Discussion}

\section{Analytical approach}

317 The annotation of identified genes with Gene Ontology categories allowed a comparison of

318 biochemical pathways and physiological processes to be made between the subtracted (SSH)

319 and unsubtracted libraries. This comparison showed that the subtracted library was enriched

320 for genes involved in processes such as metabolism, protein binding, signalling, motor

321 activity and gene transcription and translation. Some of the metabolic genes, such as those encoding for trypsin and carboxypeptidase, were also involved in moulting. These results indicate that a number of genes encoding for proteins involved in growth, feeding and swimming activity were expressed at levels greater in krill incubated in a LD photoperiod than in krill incubated in a DD photoperiod. To clarify the differences in gene expression between LD and DD krill further, qPCR was used on 11 genes highlighted by the SSH procedure that were linked to moulting, feeding and motor activity (Table 1). All 11 genes selected from the SSH library for qPCR were found to have expression levels higher in pooled LD krill compared to pooled DD krill. Of these, the expression of eight genes showed more than a two fold difference, which is traditionally used as a significance threshold for expression levels (Leung and Cavalieri, 2003).

\section{Functions of genes}

334 The most striking differential gene expression patterns were shown by the proteases, serine 335 collagenase precursor, trypsin, and CUB-serine protease. Proteases play a major role in the 336 digestive system of invertebrates (Muhlia-Almazán et al. 2008), and have been found in the moulting fluid of insects (Samuels et al., 1993) and crustaceans (Warner and Matheson, 338 1998) where they have been shown to degrade insect cuticle (Samuels et al., 1993). Although trypsin itself has not been shown to degrade cuticle, Klein et al. (1996) found that both 
340 trypsin mRNA and trypsin enzyme activity were at their highest levels during premoult (stage

$341 \mathrm{D}_{1}$ ) of the shrimp Penaeus vannamei.

343 It is known that during premoult in crustaceans (stages D0 to D3), the old cuticle is digested

344 and reabsorbed to recycle nutrients (Buchholz and Buchholz, 1989). The cuticle of $E$.

345 superba consists of epicuticle, exocuticle and endocuticle, with these last two layers built up

346 of stacks of laminae that consist of protein and chitin (Buchholz and Buchholz, 1989). It has

347 been proposed that, in order for the cuticle to be digested during premoult, proteases are

348 needed to degrade the protein protecting the chitin microfibers. Chitinases, such as $\beta-\mathrm{N}$ -

349 acetylglucosaminidase, can then digest the microfibers (Bade and Stinson, 1979; Fukamizo

350 and Kramer, 1985).

351

352 The low density lipoprotein receptor-related protein (LRP), found to be expressed at twice the

353 level in LD versus DD krill, is known to be involved in the degradation of the old cuticle

354 (Yochem et al. 1999). LRPs are also known to regulate the activity of extracellular proteases

355 (Krieger and Herz, 1994; Strickland et al., 1995) and so the LRP here may be required for

356 activation of the protease trypsin, that in turn is required for activation of trypsinogen

357 (Neurath, 1964), the serine collagenase precursor (Tsu and Craik, 1996) and pancreatic

358 carboxypeptidase A1 precursor (Bayes et al., 2003).

360 Other genes found to be up regulated in the LD krill are involved in carbohydrate metabolism 361 and motor activity. Aldo-keto reductase and fructose-bisphosphate aldolase are both involved 362 in glycolysis, the initial process of carbohydrate catabolism (Gabbay and Tze, 1972; Hanson 363 and Garber, 1972; Salvatore et al., 1986), and may indicate that the LD krill require more

364 energy than the DD krill. This is supported by an increase in expression of myosin light chain 
365 mRNA, a gene involved in muscle contraction (Poetter et al., 1996), suggesting that the LD

366 krill are more active than the DD krill and so require a greater energy supply.

368 The pooled-krill qPCR analysis revealed several effects of photoperiod on physiological

369 processes. Two carbohydrate metabolic genes involved in the glycolysis pathway were less

370 active in DD krill, even though the feeding environment was identical to that of LD krill (i.e.

371 natural seawater exchanged every $24 \mathrm{~h}$ ). Morris and Priddle (1984) found that the amount of

372 food in alimentary tracts decreased during wintertime, and suggested this was a function both

373 of the level of feeding activity and the availability of food. Similarly, Quetin et al. (2003)

374 concluded that daylength acting on both behavior and primary production explained $74 \%$ of

375 the variation in larval and juvenile growth rates. The contrary explanation, that daylength has

376 a direct effect on physiological state, is otherwise supported by Atkinson et al. (2002), who

377 found that late autumn krill ingested at only low rates even when offered high concentration

378 of food. Our results would support that latter explanation in that, on receipt of an appropriate

379 photoperiodic cue, krill no longer maintain physiological processes capable of digesting food.

380 This potentially reduces the cost of maintaining such systems during a time of year when

381 food is traditionally less available. Entry into this state potentially overrides local cues

382 regarding sporadic increases in feeding conditions, at least over short time intervals.

384 This analysis also found that gene expression of myosin, which is involved in motor activity,

385 was lower in krill exposed to DD than LD conditions. This may have a more immediate 386 explanation. Krill use light cues in order to synchronise upward and downward vertical

387 migrations. Under DD conditions, there is an absence of such cues and swimming activity

388 could cease. Nevertheless, Gaten et al. (2008) has demonstrated the existence of innate

389 rhythms of activity and inactivity in the absence of any light cues, which persist over a 
412 The observation that moulting is one of the first processes to be down-regulated after 7 days

413 of darkness is not entirely expected. Moulting continues throughout adult life and is believed 414 to occur in winter as well as summer (Buchholz, 1991, Quetin et al., 2003). However, Clarke

number of days. What may be more the issue in the present study is that the level of activity is much less under DD conditions, independent of any internal clock.

\section{Interaction between photoperiod and the moult cycle}

The individual krill qPCR analysis further highlighted some specific interactions between photoperiod and the moult cycle. In particular, we found that photoperiod affected the expression of protease genes (serine collagenase, trypsin and CUB-serine protease) in certain moult stages only. Specifically, there was a significant down-regulation in expression of protease genes in moult stage $\mathrm{C}$ in the DD photoperiod compared to the LD photoperiod, but no such down-regulation in moult stage D0 between photoperiods. Furthermore, cuticle CB6 gene, which is involved in the formation of the new cuticle and only expressed after apolysis (Fig. 3), did not appear to be affected by photoperiod. Serine collagenase, trypsin and CUBserine protease are all likely to be involved in the break-down of cuticle (Samuels et al. 1993, Klein et al. 1996, Warner and Matheson 1998) and so probably play an important role in the process of apolysis, when the cuticle separates from the epidermis and the first stages of old cuticle degradation begins. Our results indicate that the DD photoperiod slowed-down or even halted processes necessary for apolysis. This, in turn, implies that relatively short-term exposure to continuous darkness is sufficient to slow down or even halt the moult cycle. Apolysis appears to be a gate through which the moult cycle continues under natural activities but at which the cycle is halted when exposed to cues such as continuous darkness (Fig. 2). 
415 (1976), Morris and Priddle (1984) and Buchholz et al. (1989) all report a lowering of moult

416 rate in Antarctic krill during winter-time, corresponding to period when there is little or no

417 light. Morris and Priddle (1984) also report that there was an increased proportion of krill in

418 intermoult during this time. This agrees with the present study in terms of individuals not

419 progressing through apolysis when entering a stage of winter-time quiescence.

420

421 Significance of findings

422 Overall, our findings indicate:

423 1) that even 7 days of exposure to different photoperiodic cues during autumn produce a significant change in the transcription of genes underlying a number of physiological processes, including protease activity, cuticle degradation, cuticle formation, protein digestion, glucose metabolism, and muscle contraction

2) that many of these processes are consistent with known features of quiescence, particularly the slowing of moult rate, feeding and swimming activity.

430 Speculation on the use of cues by krill to alternate between active and quiescent stages was

431 partially addressed by Teschke et al. $(2007,2008)$ whose incubations in different

432 photoperiodic conditions were carried out over several months. The purpose of the present

433 study was to examine whether a response to photoperiodic conditions could also be initiated

434 over a shorter time interval. At $65^{\circ} \mathrm{S}$, the period of daylight decreases by 7 minutes per day, 435 or 49 minutes per week, as one passes from autumn to winter. It is therefore possible that a 436 set threshold may be passed within the period of a week and physiological cascades of non437 essential processes become halted quickly. Although our experiments take krill to the 438 extreme of continuous darkness, we demonstrate that these organisms are capable of halting 439 processes within a matter of days. Although a number of studies have investigated the 
440 process of dormancy in marine zooplankton (Dahms, 1995; Hirche, 1996), this is one of the

441 first to establish that the onset of quiescence in Antarctic krill may be particularly rapid once

442 appropriate cues have been received.

443

444 In conclusion, this study has shown that the gene expression underlying activities such as

445 moulting, feeding and swimming is reduced in Antarctic krill after seven days exposure to a

446 winter-time photoperiodic cycle. This reduction in activity levels is consistent with the

447 features of quiescence. We support the view that photoperiod plays an important role in

448 initiating the transition between active and quiescent states. Furthermore, we propose that this

449 transition can be initiated within a few days of crossing a photoperiodic threshold.

450

451

452 Acknowledgements

453 We would like to thank the captain and crew of RV Polarstern during ANTXXI-4 cruise. The

454 genomic analysis was funded by the Natural Environment Research Council Antarctic

455 Funding Initiative project AFI 7/06 'Gene function in Antarctic krill: determining the role of

456 clock-genes in synchronised behavioural patterns'. The contribution of GT was as part of the

457 British Antarctic Survey FLEXICON project on flexibility and constraints in polar life-

458 cycles. The contribution of MSC and MAST was as part of the British Antarctic Survey

459 BIOREACH project.

460 
461

462

463

464

465

466

467

468

469

470

471

472

473

474

475

476

477

478

479

480

481

482

483

484

485

\section{References}

Altschul, S.F., Madden, T.L., Schaffer, A.A., Zhang, J.H., Zhang, Z., Miller, W., Lipman, D.J., 1997. Gapped BLAST and PSI-BLAST: a new generation of protein database search programs. Nucleic Acids Res. 25, 3389-3402.

Atkinson, A., Snyder, R., 1997. Krill-copepod interactions at South Georgia, Antarctica, I. Omnivory by Euphausia superba. Mar. Ecol. Prog. Ser. 160, 63-76.

Atkinson, A., Meyer, B., Stübing, D., Hagen, W., Bathmann, U.V., 2002. Feeding and energy budgets of Antarctic krill Euphausia superba at the onset of winter - II. Juveniles and adults. Limnol. Oceanogr. 47, 953-966.

Bade, M.L., Stinson, A., 1979. Digestion of cuticle chitin during the molt of Manduca sexta (Lepidoptera, Sphingidae). Insect Biochem. 9, 221-231.

Bagnasco, S.M., Uchida, S., Balaban, R.S., Kador, P.F., Burg, M.B., 1987. Induction of aldose reductase and sorbitol in renal inner medullary cells by elevated extracellular NaCl. Proc. Natl. Acad. Sci. USA 84, 1718-1720.

Bayes, A., Sonnenschein, A., Daura, X., Vendrall, J., Aviles, F.X., 2003. Procarboxypeptidase A from the insect pest Helicoverpa armigera and its derived enzyme. Two forms with new functional properties. Eur. J. Biochem 270, 3026-3035.

Boguski, M.S., Lowe, T.M.J., Tolstoshev, C.M., 1993. dbEST - database for expressed sequence tags. Nat. Genet. 4, 332-333.

Buchholz F., 1982. Drach's moult staging system adapted for euphausiids. Mar Biol 66, 301305

Buchholz, C., Buchholz, F., 1989. Ultrastructure of the integument of a pelagic Crustacean: moult cycle related studies on the Antarctic krill, Euphausia superba. Mar. Biol. 101, $355-365$. 
Buchholz F, Morris DJ, Watkins JL (1989) Analyses of field moult data: prediction of intermoult period and assessment of seasonal growth in Antarctic krill, Euphausia superb Dana. Antarct. Sci. 1, 301-306

Buchholz, F., 1991. Moult cycle and growth of Antarctic krill Euphausia superba in the laboratory. Mar. Ecol. Prog. Ser. 69, 217-229.

Chen, T., Villeneuve, T.S., Garant, K.A., Amons, R., MacRae, T.H., 2007. Functional characterization of artemin, a ferritin homolog synthesized in Artemia embryos during encystment and diapause. FEBS J. 274, 1093-1101.

Cherkasova, V., Ayyadevara, S., Egilmez, N., Reis, R.S., 2000. Diverse Caenorhabditis elegans genes that are unregulated in dauer larvae also show elevated transcript levels in long-lived, aged, or starved adults. J. Mol. Biol. 300, 433-448.

Chinnery, F.E., Williams, J.A., 2003. Photoperiod and temperature regulation of diapause egg production in Acartia bifilosa from Southampton Water. Mar. Ecol. Prog. Ser. 263, 149-157.

Clarke A., 1976. Some observations on krill (Euphausia superba Dana) maintained alive in the laboratory. Br. Antarct. Surv. Bull 43, 111-118

Dahms, H.U., 1995. Dormancy in the Copepoda - an Overview. Hydrobiologia 306, 199-211.

Danks, H.V., 1987. Insect dormancy: an ecological perspective. Biol. Sur. Canada: 1-439

De Pittà, C., Bertolucci, C., Mazzotta, G.M., Bernante, F., Rizzo, G., De Nardi, B., Pallavinci, A., Lanfranchi, G., Costa, R., 2008. Systematic sequencing of mRNA from the Antarctic krill (Euphausia superba) and first tissue specific transcriptional signature. BMC Genomics 9, 45

Diaz-Mendoza, M., Ortego, F., Garcia de Lacoba, M., Magana, C., de la Poza, M., Farinos, G.P., Castanera, P., Hernandez-Crespo, P., 2005. Diversity of trypsins in the Mediterranean corn borer Sesamia nonagriodes (Lepidoptera: Noctuidae), revealed by 
511

512

513 Ewing, B., Hillier, L., Wendl, M.C., Green, P., 1998. Base-calling of automated sequencer

514

515

516

517

518

519

520

521

522

523

524

525

526

527

528

529

530

531

532

533

534

535

nucleic acid sequences and enzyme purification. Insect Biochem. Mol. Biol. 35, $1005-$ 1020. traces using phred. I. Accuracy assessment. Genome Res. 8, 175-185.

Ewing, B., Green, P., 1998. Base-calling of automated sequencer traces using phred. II. Error probabilities. Genome Res. 8, 186-194.

Frand, A.R., Russel, S., Ruvkun, G., 2005. Functional Genomic Analysis of C.elegans Molting. PLoS Biol. 3, e312.

Fukamizo, T., Kramer, K.J., 1985. Mechanism of chitin hydrolysis by the binary chitnase system in insect molting fluid. Insect Biochem. 15, 141-145.

Gabbay, K.H., Tze, W.J., 1972. Inhibition of Glucose-Induced Release of Insulin by Aldose Reductase Inhibitors. Proc. Natl. Acad. Sci. USA 69, 1435-1439.

Gaten, E., Tarling, G., Dowse, H., Kyriacou, C., Rosato, E., 2008. Is vertical migration in Antarctic krill (Euphausia superba) influenced by an underlying circadian rhythm? J. Genetics. 87, 473-483.

Godlewska, M., 1996. Vertical migrations of krill (Euphausia superba Dana). Pol. Arch. Hydrobiol. 14, 9-63.

Gorman, M.J., Paskewitz, S.M., 2001. Serine proteases as mediators of mosquito immune responses. Insect Biochem. Mol. Biol. 31, 257-262.

Hirano, Y., Matsuda, T., Kawaguchi, S., 2003. Breeding Antarctic krill in captivity. Mar. Freshw. Behav. Phy. 36, 259-269.

Hirche, H.J., 1996. Diapause in the marine copepod, Calanus finmarchicus - A review. Ophelia 44, 129-143.

Huntley, M.E., Nordhausen, W., Lopez, M.D.G., 1994. Elemental composition, metabolicactivity and growth of Antarctic Krill Euphausia superba during winter. Mar. Ecol. 
Prog. Ser. 107, 23-40.

537

538

Jewson, D.H., Granin, N.G., Zhdanov, A.A., Gorbunova, L.A., Bondarenko, N.A., Gnatovsky, R.Y., 2008. Resting stages and ecology of the planktonic diatom Aulacoseira skvortzowii in Lake Baikal. Limnol. Oceanogr. 53, 1125-1136.

Kawaguchi, K., Matsuda, O., Ishikawa, S., Naito, Y., 1986. A Light Trap to Collect Krill and Other Micronektonic and Planktonic Animals under the Antarctic Coastal Fast Ice. Polar Biol. 6, 37-42.

Klein, B., Le Moullac, G., Sellos, D., Van Wormhoudt, A., 1996. Molecular Cloning and Sequencing of Trypsin cDNAs from Penaeus vannamei (Crustacea, Decapoda): Use in Assessing Gene Expression during the Moult Cycle. Int. J. Biochem. Cell Biol. 28, $551-563$.

Krieger, M., Herz, J., 1994. Structures and functions of multiligand lipoprotein receptors: macrophage scavenger receptors and LDL receptor-related protein (LRP). Ann. Rev. Biochem. 63, 601-637.

Kuballa, A.V., Merritt, D.J., Elizur, A., 2007. Gene expression profiling of cuticular proteins across the moult cycle of the crab Portunus pelagicus. BMC Biology 5, 45.

Leung, Y.K., Cavalieri, D., 2003. Fundamentals of cDNA microarray data analysis. Trends Genet. 19, 649-657.

Makarov RR, Denys CJ, 1980. Stages of sexual maturity of Euphausia superba, BIOMASS Handbook Vol 11:1-11, SCOR, Cambridge, UK

Marschall, H.P., 1988. The Overwintering Strategy of Antarctic Krill under the Pack-Ice of the Weddell Sea. Polar Biol. 9, 129-135.

Morris D.J., Priddle J., 1984. Observations on the feeding and moulting of the Antarctic krill, Euphausia superba Dana, in winter. Br. Antarct. Surv. Bull. 65, 57-63

Muhlia-Almazán, A., Sánchez-Paz, A., García-Carreño, F.L., 2008. Invertebrate trypsins: a 
review. J. Comp. Physiol. B 178, 655-672.

Nagamatsu, Y., Yanagisawa, I., Kimoto, M., Okamoto, E., Koga, D., 1995. Purification of a Chitooligosaccharidolytic $\beta-N$-Acetylglucosaminidase from Bombyx mori Larvae during Metamorphosis and the Nucleotide Sequence of its cDNA. Biosci. Biotech. Biochem. 59, 219-225.

Neurath, H., 1964. Mechanism of zymogen activation. Fed. Proc. 23, 1.

Ote, M., Mita, K., Kawasaki, H., Daimon, T., Kobayashi, M., Shimada, T., 2005. Identification of molting fluid carboxypeptidase A (MF-CPA) in Bombyx mori. Comp. Biochem. Phys. B 141, 314-322.

Parkinson, J., Anthony, A., Wasmuth, J., Schmid, R., Hedley, A., Blaxter, M., 2004. PartiGene - constructing partial genomes. Bioinformatics 20, 1398-1404.

Pfaffl, M.W., 2001. A new mathematical model for relative quantification in real-time RTPCR. Nucleic Acids Res. 29, 2002-2007.

Pijanowska, J., Stolpe, G., 1996. Summer diapause in Daphnia as a reaction to the presence of fish. J. Plankton Res. 18, 1407-1412.

Poetter, K., Jiang, H., Hassanzadeh, S., Master, S.R., Chang, A., Dalakas, M.C., Rayment, I., Sellers, J.R., Fananapazir, L., Epstein, N.D., 1996. Mutations in either the essential or regulatory light chains of myosin are associated with a rare myopathy in human heart and skeletal muscle. Nat. Genet. 13, 63-69.

Purać, J., Burns, G., Thorne, M.A.S., Grubor-Lajšić, G., Worland, M.R., Clark, M.S., 2008. Cold hardening processes in the Antarctic springtail, Cryptopygus antarcticus: Clues from a microarray. J. Insect Physiol. 54, 1356-1362.

Quetin, L.B., Ross, R.M., Frazer, T.K., Amsler, M.O., Wyattevens, C., Oakes, S.A., 2003. Growth of larval krill, Euphausia superba, in fall and winter west of the Antarctic Peninsula. Mar. Biol. 143, 833-843. 
586 Robich, R.M., Rinehart, J.P., Kitchen, L.J., Denlinger, D.L., 2007. Diapause-specific gene expression in the northern house mosquito, Culex pipens L., identified by supressive subtractive hybridisation. J. Insect Physiol. 53, 235-245.

Rozen, S., Skaletsky, H.J., 2000. Primer3 on the WWW for General Users and for Biologist Programmers. In: Misener, S., Krawetz, S.A. (Eds.), Bioinformatics Methods and Protocols: Methods in Molecular Biology. Humana Press Inc, Totowa, NJ, pp. 365386.

Salvatore, F., Izzo, P., Paolella, G., 1986. Aldolase gene and protein families: structure, expression and pathophysiology. In: Blasi, F. (Ed.), Horizons in Biochemistry Biophysics. John Wiley and Sons, Chichester, pp. 611-665.

Samuels, R.I., Charnley, A.K., Reynolds, S.E., 1993. A Cuticle-Degrading Proteinase from the Moulting Fluid of the Tobacco Hornworm, Manduca sexta. Insect Biochem. Molec. 23, 607-614.

Samuels, R.I., Reynolds, S.E., 1993. Molting Fluid Enzymes of the Tobacco Hornworm, Manduca sexta: Timing of Proteolytic and Chitinolytic Activity in Relation to PreEcdysial Development. Arch. Insect Biochem. 24, 33-44.

Schnackschiel, S.B., Hagen, W., 1994. Life-Cycle Strategies and Seasonal-Variations in Distribution and Population-Structure of 4 Dominant Calanoid Copepod Species in the Eastern Weddell Sea, Antarctica. J. Plankton Res. 16, 1543-1566.

Slusarczyk, M., Rygielska, E., 2004. Fish faeces as the primary source of chemical cues inducing fish avoidance diapause in Daphnia magna. Hydrobiologia 526, 231-234.

Strickland, D.K., Kounnas, M.Z., Argraves, W.S., 1995. LDL receptor-related protein: a multiligand receptor for lipoportein and proteinase catabolism. FASEB J. 9, 890-898.

609 Tande, K.S., Hopkins, C.C.E., 1981. Ecological Investigations of the Zooplankton 
finmarchicus and the Role of Gonad Development in Overwintering Strategy. Mar. Biol. 63, 159-164.

613 Tarrant, A.M., Baumgartner, M.F., Verslycke, T., Johnson, C.L., 2008. Differential gene expression in diapausing and active Calanus finmarchicus (Copepoda). Mar. Ecol. Prog. Ser. 355, 193-207.

616 Teschke, M., Kawaguchi, S., Meyer, B., 2007. Simulated light regimes affect feeding and metabolism of Antarctic krill, Euphausia superba. Limnol. Oceanogr. 52, 1046-1054.

618 Teschke, M., Kawaguchi, S., Meyer, B., 2008. Effects of simulated light regimes on maturity and body composition of Antarctic krill, Euphausia superba. Mar. Biol. 154, 315-324.

620 The Gene Ontology Consortium, 2000. Gene Ontology: tool for the unification of biology. Nat. Genet. 25, 25-29.

Tsu, C.A., Craik, C.S., 1996. Substrate Recognition by Recombinant Serine Collagenase 1 from Uca pugilator. J. Biol. Chem. 271, 11563-11570.

Warner, A.H., Matheson, C., 1998. Release of Proteases from Larvae of the Brine Shrimp Artemia franciscana and Their Potential Role During the Molting Process. Comp. Biochem. Phys. B 119, 255-263.

627

Wei, Z., Youping, Y., Zhang, B., Wang, Z., Peng, G., Cao, Y., Xia, Y., 2007. Cloning of a 628 novel protease required for the moulting of Locusta migratoria manilensis. Dev. Growth Differ. 49, 611-621.

630 Yochem, J., Tuck, S., Greenwald, I., Han, M., 1999. A gp330/megalin-related protein is required in the major epidermis of Caenorhabditis elegans for completion of molting. Development 126, 597-606. 


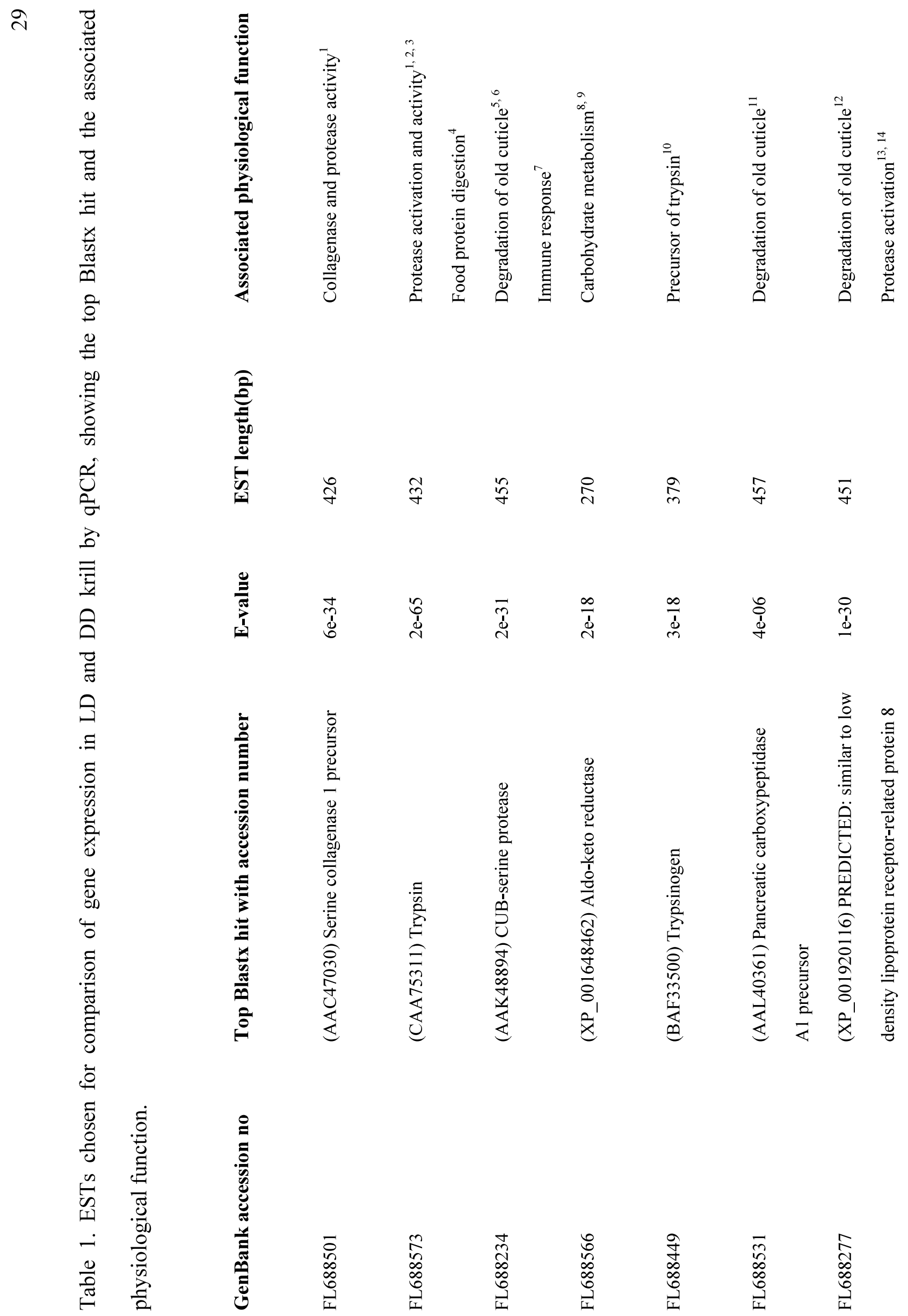


요

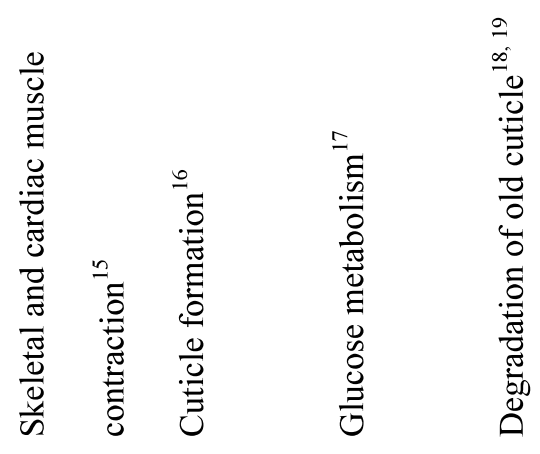

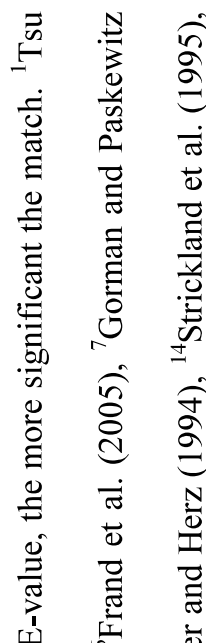

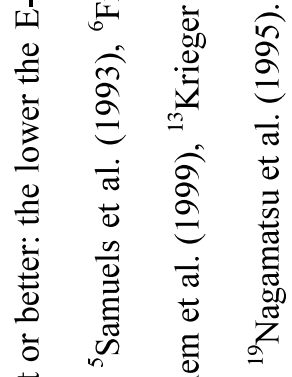

i $\bar{m}$ \&

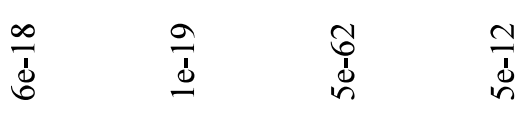

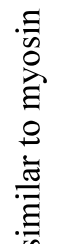

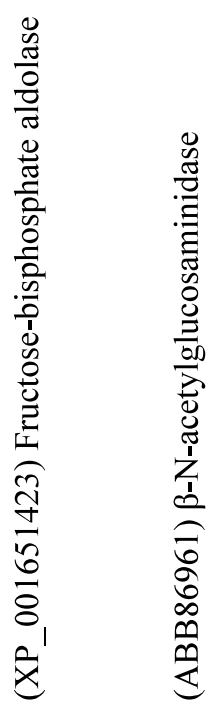

节高

ลิ

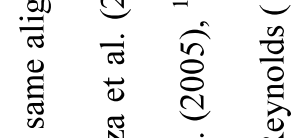

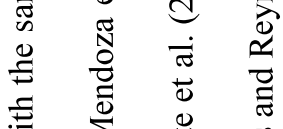

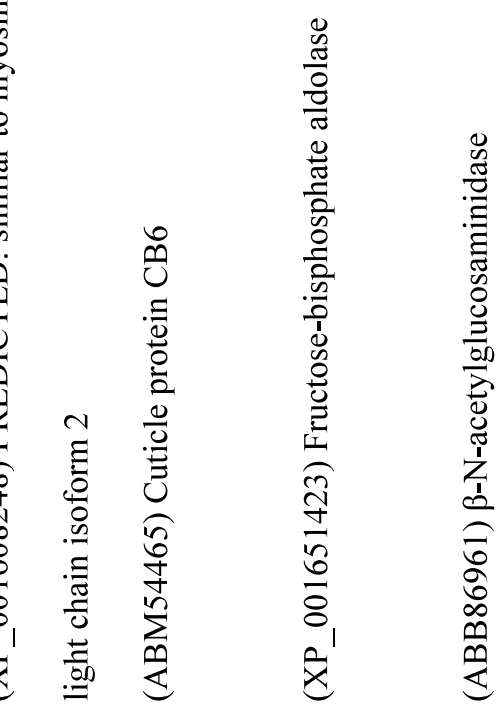

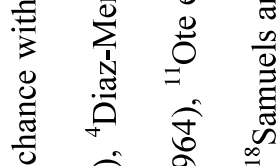

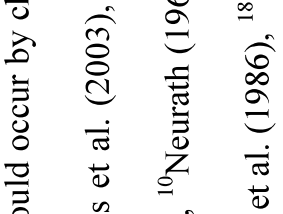

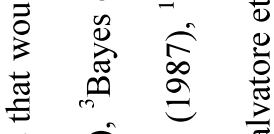

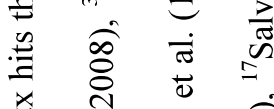

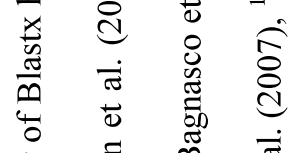

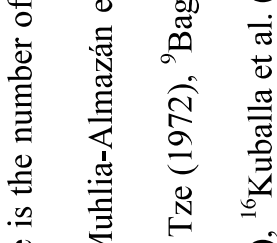

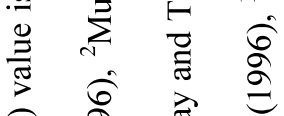

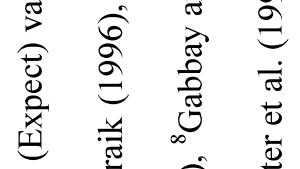

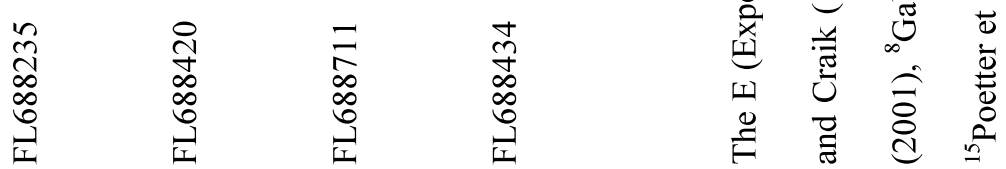


Table 2. Comparisons carried out on individual krill to examine the effects of light regime and moult stage on the expression of genes involved in moulting

\begin{tabular}{|l|l|l|l|}
\hline $\begin{array}{l}\text { qPCR- } \\
\text { comparison } \\
\text { experiment }\end{array}$ & Purpose & Control Group & Test Group \\
\hline A & $\begin{array}{l}\text { Effect of apolysis on } \\
\text { gene expression }\end{array}$ & $\begin{array}{l}\text { 6 krill } \\
\text { moult stage C } \\
\text { light regime 3LD \& 3DD }\end{array}$ & $\begin{array}{l}\text { 3 krill } \\
\text { moult stage D0 } \\
\text { light regime 3LD \& 3DD }\end{array}$ \\
\hline B & $\begin{array}{l}\text { Effect of light regime } \\
\text { on gene expression in } \\
\text { moult stage C }\end{array}$ & $\begin{array}{l}6 \text { krill } \\
\text { moult stage C } \\
\text { light regime LD }\end{array}$ & $\begin{array}{l}\text { moult stage C } \\
\text { light regime DD }\end{array}$ \\
\hline C & $\begin{array}{l}\text { Effect of light regime } \\
\text { on gene expression in } \\
\text { moult stage D0 }\end{array}$ & $\begin{array}{l}3 \text { krill } \\
\text { moult stage D0 } \\
\text { light regime LD }\end{array}$ & $\begin{array}{l}3 \text { krill } \\
\text { moult stage D0 } \\
\text { light regime DD }\end{array}$ \\
\hline
\end{tabular}


Table 3. Primer sequences used in qPCR.

Gene name

Serine collagenase 1 precursor

Trypsin

CUB-serine protease

Aldo-keto reductase

Trypsinogen

F: ACTTGGAGGAGCACAGGTTG

Pancreatic carboxypeptidase A1

F: GCCTACAAACAGGGTGTTCC

precursor

Low density lipoprotein

F: ATTTGCCGCTGCTTTTACAT

Myosin light chain isoform 2

F: GTCGATGAGGACACCCAGAT

Cuticle protein CB6
F: GGTTCATGTGACCACACTCG

R: ATCACCATTGCAGGAACCAT

F: ATGCCTATGGTGAGGGTGAG

R: GGTAGTTGGGTCTGGCACAT

F: AGCCCGATGTATTGATGGAG

R: TAGAAGAGAGGGCCACCAGA

F: TTTCAGATTCAACGCAATGTG

R: GCTGCACACTCGACCATTAC

R: GGCAGATCGGAGTTGTGTCT

R: GCTTCAGGAACAAGTTCACCA

R: AGTGCATACCCGGCAACTAC

R: TGGTTGAGGCTACTGGAACC

F: ACCAAAGTCGTTGCCTGAGT

Product size (bp)

112

174

147

R: CGACACGACACACATCATCA 
Fructose-bisphosphate aldolase

F: AATGTAACACCGGGAACTGC

160

R: TCGCTGATCACAACGTCTTC

ß-N-acetylglucosaminidase

F: AGTGTTCTGCCGATTTTGGT

169

R: TCCTCAACAGACCCACTTCC

Beta actin

F: GGAGACCGCAAGATTCCATA

R: TGAGCAGGAAATGACCACAG

Phosphoenolpyruvate

F: TGTTGAAGGTAGTGGCCAAA

138

carboxykinase

R: GAAACACGGTGTCATGGTTG

Glyceraldehyde 3-phosphate

F: GATGCCAAAGCTGGCATTAT

166

dehydrogenase

R: TTGTCCACGACAGCAGAAAA 
Table 4. General features of subtracted and unsubtracted cDNA libraries.

\section{LD-DD subtracted}

595

129

466

225

241

\section{LD unsubtracted}

685

111

574

232

342

Unidentified 
Table 5. Significantly enriched GO slim categories in subtracted library compared to unsubtracted library $(\mathrm{p}<0.05)$.

\section{GO description}

Binding

Receptor activity

Transferase activity

Protein binding

Lyase activity

Macromolecule metabolic process

Metabolic process
LD-DD subtracted

240

49

55

196

31

225

76

\section{LD unsubtracted}

159

14

23

132

10

160

41 p value

$1.35 \mathrm{E}-05$

0.0003

0.0058

0.0102

0.0116

0.0171

0.0263 
Fig. 1. Schematic representation of 24 hour light regimes in the experimental tanks. LD: 12 hours of light and 12 hours of darkness; DD: continuous darkness. Arrows indicate the approximate time of sunrise and sunset in the natural environment at the time of the experiment

Fig. 2. The moult cycle of Euphausia superba showing the specific moult stage (stages A to D3) and moult category (pre-, inter- and post-moult). Individuals in DD photoperiod that are between moult and apolysis do not enter and pass through apolysis. Individuals in DD that are beyond apolysis continue on to moult. Individuals in LD progress normally through the full moult cycle.

Fig. 3. Differential gene expression between pools of LD and DD krill sampled over a 24 hour period, normalised to $\beta$-actin. Data indicate the level of up-regulation of genes in LD krill compared to the level expressed in DD krill.

Fig. 4. Effect of light regime on gene expression in moult staged individual krill normalised to PEP-CK. Gene expression is represented as a $\log _{2}$ relative expression ratio (means $\pm \mathrm{SE}$ ). (A) $\mathrm{LD} / \mathrm{DD}$ stage $\mathrm{C}$ vs $\mathrm{LD} / \mathrm{DD}$ stage $\mathrm{D}_{0}(\mathrm{n}=6)$; a positive value indicates the level of upregulation of krill in moult stage D0 compared to the level of expression in moult stage $\mathrm{C}$ krill. (B) LD stage $C$ vs DD stage $C(n=6)$; positive values indicates up-regulation and negative values, down-regulation in DD krill relative to LD krill (C) LD stage $\mathrm{D}_{0}$ vs DD stage $\mathrm{D}_{0}(\mathrm{n}=3)$; positive and negative values as for $(\mathrm{B})$;. An asterisk indicates significant results $(\mathrm{P}<0.05)$. 


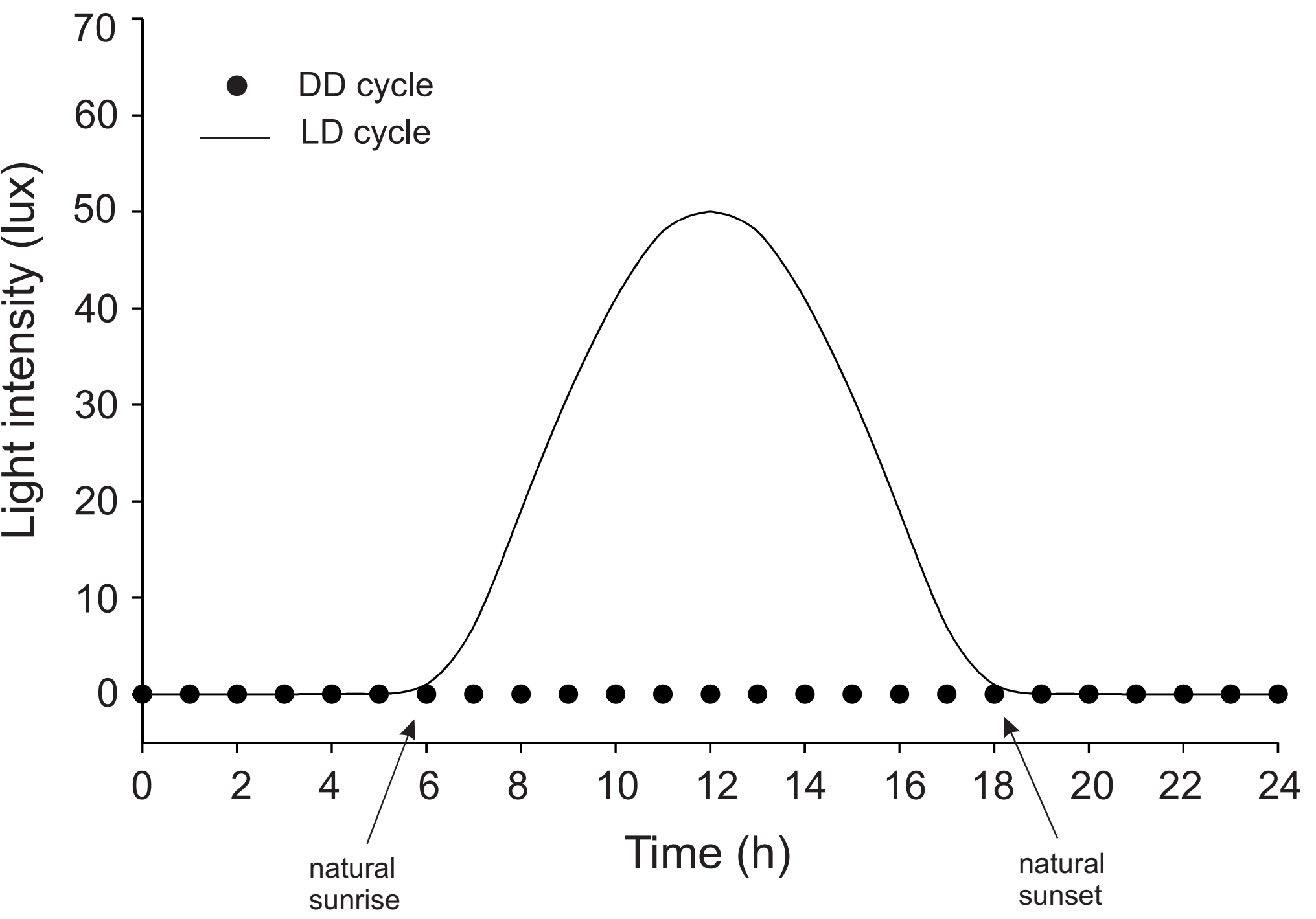


Figure 2

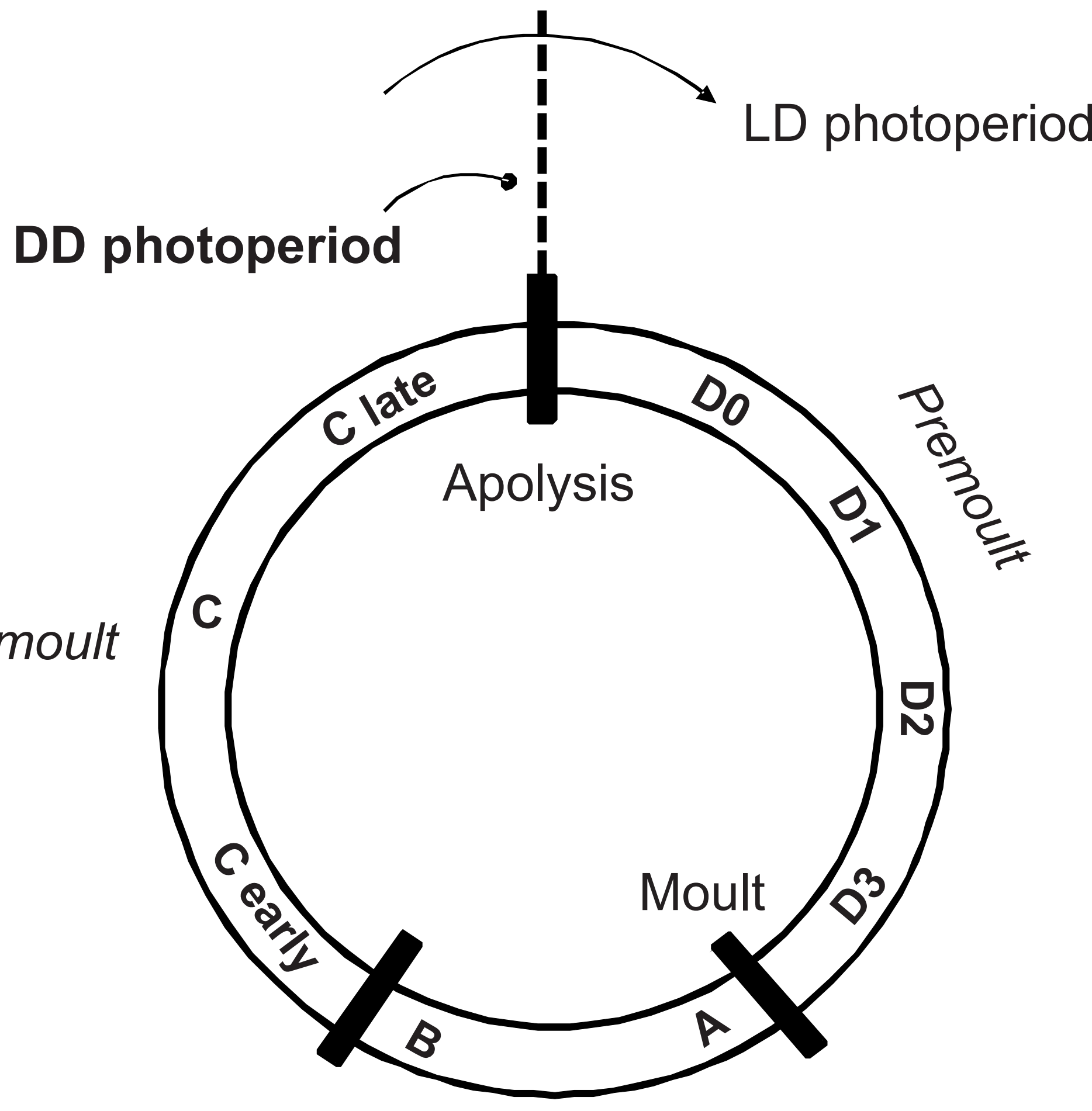

Postmoult 
Figure 3
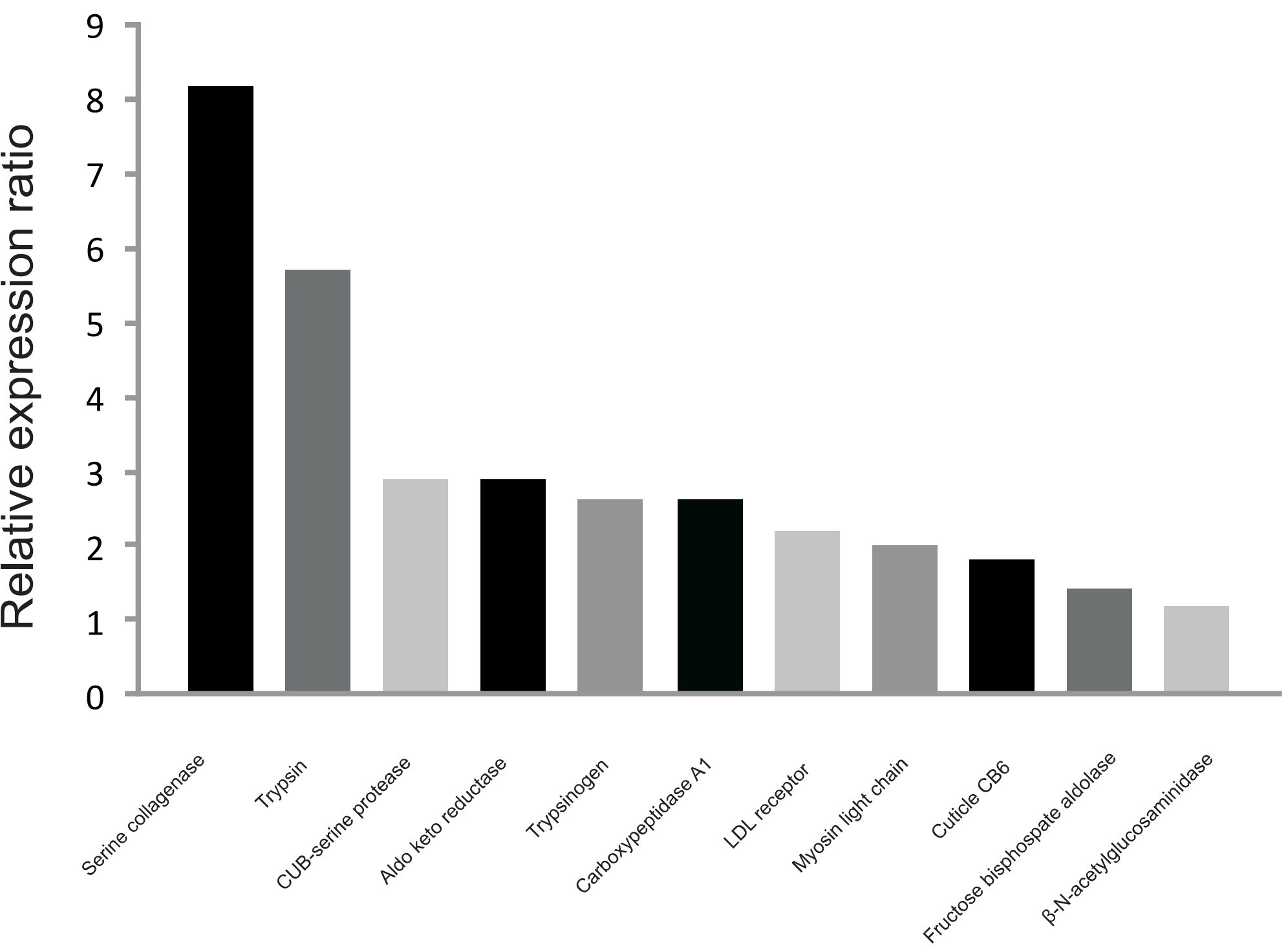

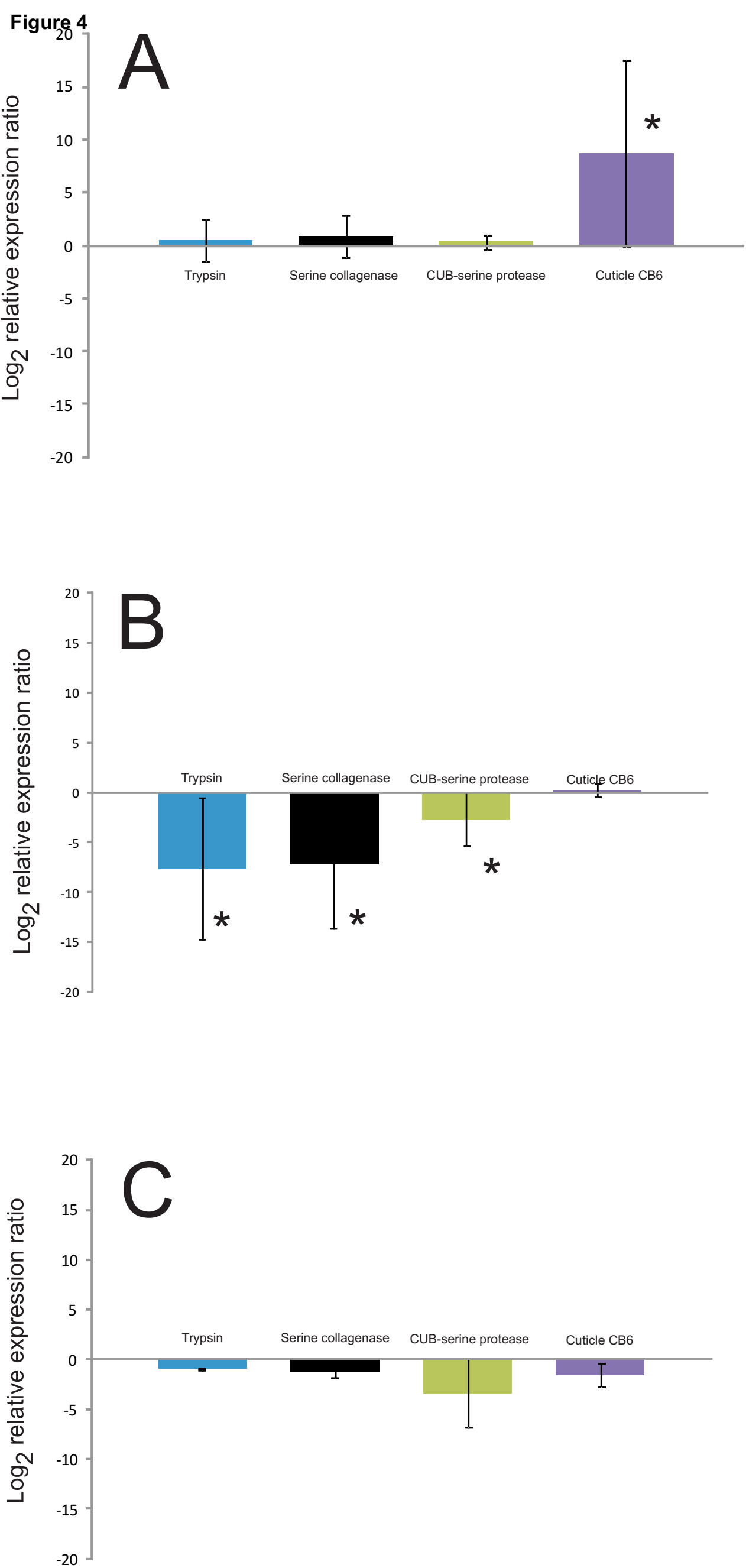